\title{
Determination of Gemfibrozil (Lipitor and Lopid) in Water, Biological Fluids and Drug Matrix by Dispersive Liquid-Liquid micro Extraction (DLLME) and Liquid Chromatography
}

\author{
A.Ghorbani ${ }^{1}$,M.Dayani ${ }^{2}$ \\ ${ }^{1}$ Department of chemistry, Saveh Branch, Islamic Azad University, Saveh, Iran \\ ${ }^{2}$ Department of chemistry, Saveh Branch, Islamic Azad University, Saveh, Iran
}

\begin{abstract}
In this study Dispersive liquid-liquid micro extraction (DLLME) coupled with High performance liquid chromatography was applied for the determination of Gemfibrozil in water, drug's matrix and biological liquids (human plasma and urine). In this method, the appropriate mixture of extraction solvent (200 $\mu \mathrm{l}$ chlorophorm) and disperser solvent $(1 \mathrm{ml}$ methanol) are injected rapidly into the aqueous sample $(10.0 \mathrm{ml})$ by syringe, cloudy solution is formed that consisted of fine particles of extraction solvent which is dispersed entirely into aqueous phase. The mixture was centrifuged and the extraction solvent is sedimented on the bottom of the conical test tube. $50 \mu \mathrm{l}$ of the sedimented phase is puted in a vial and it's solvent is evaporated. Then $1 \mathrm{ml}$ methanol injected to vial and $20 \mu \mathrm{L}$ of it injected into the HPLC for separation and determination of Gemfibrozil. Some important parameters, such as kind of extraction and disperser solvent, volume of them, extraction time, $\mathrm{pH}$ and ionic strength of the aqueous feed solution were optimized. Under the optimum conditions, the enrichment factors and extraction recoveries were 10 and $93.64 \%$. The linear range was $\left(0.1-100.0 \mathrm{mgl}^{-1}\right)$, limit of detection was $12.3 \mathrm{mgl}^{-1}$. The relative standard deviations (RSD) for 2 $\mathrm{mgl}^{-1}$ of Gemfibrozil in water were $1.3 \%,(\mathrm{n}=10)$.
\end{abstract}

Keyword: Dispersive liquid-liquid micro extraction (DLLME), Gemfibrozil, biological samples.

\section{Introduction}

Gemfibrozil; 5-(2,5-dimethylphenoxy); 2,2dimethylpentanoic acid is a lipid and cholesterol modifying medicine (Tatar, 2006).

Owing to the low concentration of target drugs and the complex matrices of urine and plasma samples, the pretreatment of a sample is usually required prior to the instrumental analysis. Conventional sample preparation methods, like liquid-liquid extraction (LLE) and solid phase extraction (SPE) (Xu et al., 2007 ) (pena-pereira et al., 2009), have been applied for the sample preparation. However, the former tends to be time-consuming and amount of organic solvent, and the latter need sapecific pump device that can be relatively expensive. Recently, some new micro extraction techniques, such as hollow fiber-based liquid phase extraction (Arthur and Pawliszyn, 1990), fiber in-tube solid-phase micro extraction (Psillakis and Kalogerakis, 2002) solid phase extraction disks and molecularly imprinted polymer (Vlataki et al., 1993) have been proposed for the separation and pre-concentration of drugs from biological fluids. Dispersive liquid-liquid micro extraction (DLLME) as a novel liquid micro extraction with less solvent consumption, was reported as green sample pretreatment (Rezaee et al., 2006). DLLME is based on a ternary component solvents extraction system, including dispersive solvent, extraction solvent and aqueous samples containing target analyte. It possesses many advantages: simple, rapid, cheap, high enrichment factor, high recovery, etc. Up to now, DLLME has been widely applied for the assay of environmental water samples and it also shows good prospect in the analysis of analytes in complex matrices such as biological fluids (Berijani et al., 2006). So, In this study DLLME coupled with High performance liquid chromatography was applied for the determination of Gemfibrozil in water, drug's matrix and biological liquids (human plasma and urine).

\section{Materials and method}

The GEM standard was obtained from Alborz bulk pharamacooheia (Saveh,Iran). All reagents were of analytical reagent grade, Methanol, Ethanol, acetonitrile, Acetone and Isopropanol used as dispersing solvents and Chloroform, Carbon tetrachloride, Dichoromethan and Dichloroethan as used extractive solvents were HPLC grade from Merck (Darmstadt, Germany). Ultra pure water (Milli-Q plus system, Millipore, Bedford, MA, USA) was 
used throughout the work. Sodium hydroxide and Sodium chloride were obtained from Merck (Darmstadt, Germany). The sample buffer solutions were prepared from acetic acid and sodium acetate, ammonia and ammonium chloride from Merk (Darmstadt, Germany).

\section{Chromatography condition}

Chromatography was preformed using a Thermo sepration products HPLC (Agilent, Germany) Model 1200 solvent delivery system, a Rheodyne injection valve with a $20 \mu \mathrm{l}$ loop, and UV detector. The liquid chromatograph is equipped with a $276-\mathrm{nm} \times 25$-cm column that contains packing $\mathrm{L} 1\left(\mathrm{C}_{18}\right)$. The flow rate is about $1 \mathrm{ml}$ per min. A mixture of glacial acetic acid and methanol used as mobile phase.

\section{DLLME Procedure}

The sample solution $(10 \mathrm{ml})$ containing the interests was placed in a $15 \mathrm{ml}$ glass test tube with conical bottom. $1 \mathrm{ml}$ of Methanol (as disperser solvent) containing $200 \mu \mathrm{l}$ $\mathrm{CHCl}_{3}$ (as extraction solvent) was rapidly and vigorously injected into the sample solution using a $2.00 \mathrm{ml}$ syringe. A cloudy water-Methanol- $\mathrm{CHCl}_{3}$ mixture was consequently formed. Then the mixture was gently shaken. In order to separate the phases, the mixture was centrifuged for $3 \mathrm{~min}$ at $3000 \mathrm{r} / \mathrm{min}$. After this step, the observed phenomena for different samples were noted. For aqueous standards, the extraction solvent $\left(\mathrm{CHCl}_{3}\right)$ was sedimented at the bottom of the conical test tube. While, for urine samples, white lipid solid was sedimented, probably due to the co-sedimentation of the urine matrixes (like uric acid, carbamide) at high $\mathrm{pH}$ value. In this study, the sedimented phase was dissolved by $1 \mathrm{ml}$ of mobile phase after carefully discarding the supernatant solution. Then the extract solution was filtrated through a $0.45 \mu \mathrm{m}$ filter to eliminate the white floccule. Twenty micro liter of the extracts injected into the HPLC for consequent analysis.

\section{Results and discussion \\ Optimization of DLLME parameters}

To obtain high extraction efficiency, it is necessary to investigate the effect of all parameters that can probably influence the performance of extraction. In DLLME method, these parameters include the type and the volume of the extraction and the disperser solvent, salt adition, $\mathrm{pH}$ and extraction time. The peak area of the analytes was used to evaluate the extraction efficiency under different conditions. Pre-concentration factor (PF) or Enrichment factor (EF) and percent extraction recovery $(\mathrm{ER} \%)$ were used to assess the method optimized parameters as decribed by Rezaee et al. (Meng et al., 2010) as analytical responses ware calculated based on the following equations:

$E F=C_{\text {sed }} / C_{\text {o }}$

$E R=\left(C_{\text {sed }} V_{\text {sed }}\right) /\left(C_{\mathrm{o}} V_{\text {aq }}\right)$

Where $\mathrm{C}_{\text {sed }}$ and $\mathrm{C}_{0}$ are concentration of the analyte in the sedimented phase and initial concentration of the analyte in the aqueous sample, respectively. $\mathrm{V}_{\text {sed }}$ and $\mathrm{V}_{\mathrm{aq}}$ are the volume of the sedimented phase and volume of the aqueous sample. $\mathrm{C}_{\text {sed }}$, for each micro extraction solvent, was calculated on the calibration graph which obtained from conventional liquid- liquid extraction (LLE) combined with spectrofluorimetry.

\section{Selection of the extraction and disperser solvent}

The type of extraction solvent in DLLME is an essential parameter for efficient extraction. According to the DLLME principles, the selection of extraction solvent should have special characteristics including (a) extraction capability of interest compounds, (b) low solubility in water, (c) higher density than aqueous phase, (d) formation of tiny droplets in presence of a dispersive solvent, and (e) good chromatographic behavior (Meng et al., 2010). Based on these considerations, Chloroform displayed the highest extraction efficiency and the lowest relative standard deviation. $\mathrm{CHCl}_{3}$ was selected as the optimum extraction solvent (Fig.1).

Fig.1. Effect of the extraction solvent type on $\%$

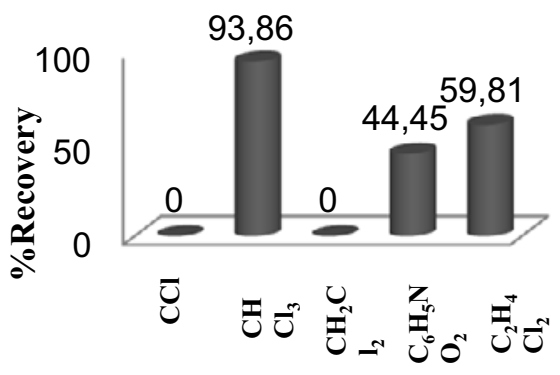

EXtraction solvent

Recovery

Disperser solvent is soluble in extraction solvent and should be miscible in water, thus enabling the extraction solvent to be dispersed as fine particles in aqueous phase to form a cloudy solution. Methanol was selected as disperser solvent (Fig.2).

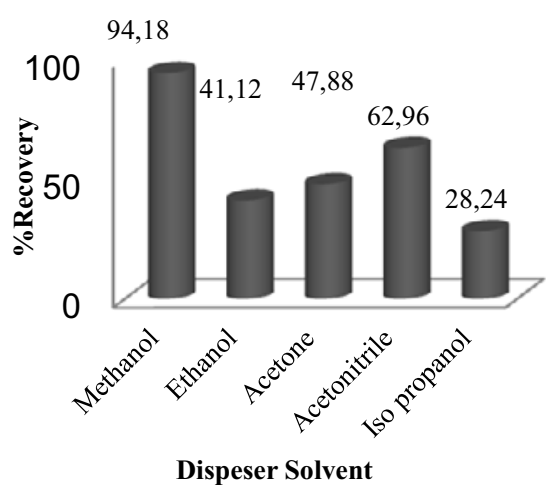

Fig.2. Effect of the dispeser solvent type on \% Recovery 


\section{Salt addition}

The influence of ionic strength on the performance of DLLME was investigated by adding different amounts of

\begin{tabular}{|c|c|c|c|c|}
\hline $\mathrm{EF}$ & $\% \mathrm{ER}$ & $\begin{array}{c}\mathrm{C}_{\text {sed }} \\
\left(\mathrm{mgl}^{-1}\right)\end{array}$ & $\begin{array}{c}\text { Area (mv or } \\
\mathrm{mAU})\end{array}$ & $\begin{array}{c}\mathrm{Con} \\
\left(\mathrm{mgl}^{-1)}\right.\end{array}$ \\
\hline 9.22 & 92.5 & 0.92 & 5.97 & 0.1 \\
\hline 9.12 & 91.20 & 9.12 & 59.02 & 1 \\
\hline 9.30 & 93.0 & 46.5 & 300.92 & 5 \\
\hline 9.21 & 92.09 & 460.45 & 2980.01 & 50 \\
\hline 9.06 & 90.59 & 905.90 & 5863.17 & 100 \\
\hline
\end{tabular}

$\mathrm{NaCl}(0-10 \%, \quad w / \mathrm{v})$ under the previous optimum conditions. Increase on recoveries of GEM was observed when the ionic strength was increased. As a consequence, DLLME was carried out with addition of salt (7\%).

\section{Effect of pH}

In this study, the effect of the $\mathrm{pH}$ upon Gemfibrozil extractability with DLLME was investigated by varying the $\mathrm{pH}$ values from 1.0 to 13.0. Best recovery observed at pH 3.0. (Fig.4).

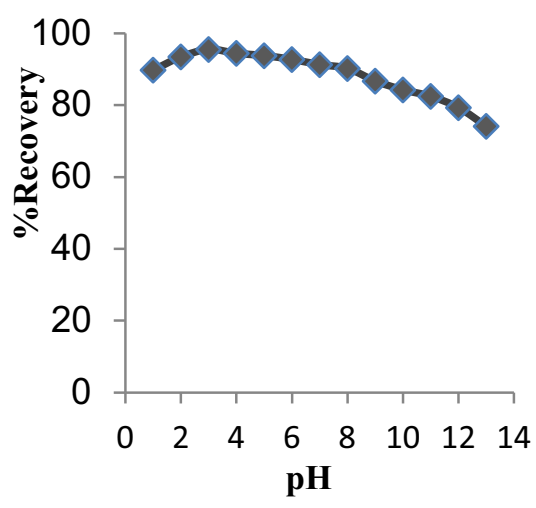

Fig.4. Effect of the $\mathrm{pH}$ on \% Recovery

\section{Effect of extraction time}

In DLLME, extraction time is defined as interval time between the injection of the mixture of disperser solvent (methanol) and extraction solvent (chloroform), and before starting to centrifuge. The effect of extraction time was examined in the range of 0 to 15 min under constant experimental conditions. The obtained results showed that the extraction time had no significant influence on the peak area of gemfibrozil. Therefore, the DLLME method was time independent, which was the most important advantage of this technique. (Fig.5).

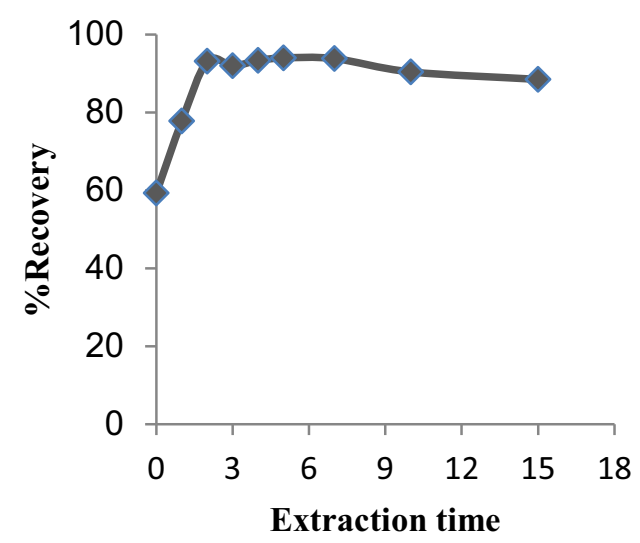

Fig.5. Effect of the Extraction time on \% recovery

\section{Analytical figure of merit}

In the table 1 showing calibration data for GEM, with results from statistical analysis.

Table 1. Summary of validation results.

\begin{tabular}{|c|c|}
\hline Parameter & $\begin{array}{c}\text { Amount } \\
\text { analytical }\end{array}$ \\
\hline Liner range $\left(\mathrm{mgl}^{-1}\right)$ & $0.1-100$ \\
\hline Regressions equations & $Y=2.4491 X+6.65$ \\
\hline Correlation coefficient (r) & 0.9991 \\
\hline $\begin{array}{c}\text { Detection Limit [LOD] } \\
\left(\mathrm{mgl}^{-1)}\right.\end{array}$ & 12.3 \\
\hline $\begin{array}{c}\text { Limit of quantification } \\
{[\mathrm{LOQ}]\left(\mathrm{mgl}^{-1}\right)}\end{array}$ & 41 \\
\hline $\mathrm{RSD} \% \mathrm{n}=10$ & $\% 1.3$ \\
\hline $\begin{array}{c}\text { Pre-concentration factor (10 } \\
\text { ml sample) }\end{array}$ & 10 \\
\hline (\%) Avrage Recovery & 93.64 \\
\hline
\end{tabular}

\section{Extraction of Gemfbrozil in biological samples (Human urine and plasma)}

In table 2 and 3 , showing the pre-concentration of the proposed method is good for extraction of Gem in Urine and Plasma samples.

Table 2. Results from determination of method accuracy for urine samples.

\begin{tabular}{|c|c|c|c|c|}
\hline EF & $\begin{array}{c}\text { Recovery } \\
\%\end{array}$ & $\begin{array}{c}\mathrm{C}_{\text {sed }} \\
\left(\mathrm{mgl}^{-1}\right)\end{array}$ & Area & $\begin{array}{c}\text { Conc } \\
\left(\mathrm{mgl}^{-1}\right)\end{array}$ \\
\hline 9.21 & 92.15 & 0.92 & 5.63 & 0.1 \\
\hline 9.12 & 91.21 & 91.21 & 557.26 & 10 \\
\hline 9.09 & 90.89 & 181.78 & 1110.6 & 20 \\
\hline
\end{tabular}


Table 3. Results from determination of method accuracy for plasma samples.

\begin{tabular}{|c|c|c|c|c|}
\hline EF & \%Recovery & $\begin{array}{c}\mathrm{C}_{\text {sed }} \\
\left(\mathrm{mgl}^{-1}\right)\end{array}$ & $\begin{array}{c}\text { Area } \\
(\mathrm{mv} \text { or } \\
\mathrm{mAU})\end{array}$ & $\left(\mathrm{mgl}^{-1}\right)$ \\
\hline 9.31 & 93.12 & 0.93 & 5.65 & 0.1 \\
\hline 9.19 & 91.89 & 45.94 & 278.77 & 5 \\
\hline 9.14 & 91.4 & 91.40 & 554.52 & 10 \\
\hline 9.10 & 91.09 & 910.90 & 5527.03 & 100 \\
\hline
\end{tabular}

\section{Extraction of Gemfibrozil in drug matrix}

Table 4, showing the pre-concentration of the proposed method for extraction of Gem in drug matrix.

Table 4. Results from determination of method accuracy for drug matrix.

\section{Conclusions}

This paper describes a DLLME-LC-UV method for the analysis of Gemfibrozil in water, biological fluids and matrix drugs. This method has an acceptable relative recovery $(93.64 \%)$ with \% $\mathrm{RSD}(1.3 \%)$ and a liner ranges $\left(0.1-100 \mathrm{mgl}^{-1}\right)$ for the determination of Gem .
In this method, sample preparation time as well as consumption of toxic organic solvents have been minimized without affecting the sensitivity of the method. Compared to other extraction methods such as SPE and SPME, the presented method has lower LOQ and much shorter extraction time. This method is also convenient, cost effective and sensitive, which can be used for the determination of GEM in biological fluids and water samples.

\section{References}

Tatar S. Chromatographia. 2006; 64:447-451

$\mathrm{Xu}$ L. Basheer C. Lee H.K. Chromatogr. A. 2007;1152:184.

Pena-pereira F. lavilla I. Bendicho C. Spetrochim, Acta. 2009; Part B:1.

Arthur C.L. Pawliszyn J. Anal. Chem. 1990; 62-2145.

Psillakis E. Kalogerakis N. Trends Anal. Chem. 2002; 21(1):53-63.

Vlatakis G. Andersson LI. Muller R. Mosbach K. Nature, 1993; 361:645-647.

Rezaee M. Assadi Y. Milani Hosseini M R. Aghaee E. Ahmadi F. Berijani S. J. Chromatogr. A. 2006; 1116:1-9.

Berijani S. Assadi Y. Anbia M. Milani Hosseini M R. AghaeeE. Chromatogr. A. 2006; 1123:1-9.

United State Pharmacopeia (USP 34).

Meng L. Wang B. Luo F. Shen G. Wang Z. Guo M. Forensic Science internation. 2010; 6286:1-6. 